\title{
Knowledge, Attitudes, and Beliefs Regarding Breast and Cervical Cancer Screening among Cambodian, Laotian, Thai, and Tongan Women
}

\author{
Jeff Dang • Jessica Lee • Jacqueline H. Tran
}

Published online: 18 March 2010

(C) The Author(s) 2010. This article is published with open access at Springerlink.com

\begin{abstract}
Asian American Pacific Islander (AAPI) groups have low rates of breast and cervical cancer screening. This study examined knowledge, attitudes, and beliefs (KABs) regarding breast and cervical cancer on AAPI women. A cross-sectional survey of 1,808 AAPI women was included. Descriptive statistics and chi-square tests were provided and $55.3 \%, 68.6 \%$, and $71.9 \%$ had received mammograms, clinical breast exam, and Pap smears, respectively. KABs on breast and cervical cancer varied between the four ethnic groups. Understanding the KABs toward cancer screening among AAPI women holds promise for identifying barriers to early detection and could aid in the creation of interventions.
\end{abstract}

Keywords Knowledge $\cdot$ Attitudes $\cdot$ Beliefs .

Breast and cervical cancer

Contributors J. Dang initiated the article, led the writing, and data analysis. J. Lee assisted with data analysis and writing the article. J. H. Tran is a member of the PATH for Women team and was involved in the initial project development including study design, interpretation of findings, and writing of the article.

J. Dang $(\bowtie)$

Consulting Measurement Group, Inc,

2390 Crenshaw Blvd. \#110,

Torrance, CA 90501, USA

e-mail: jdang@webcmg.com

J. Lee

Consulting Measurement Group, Inc,

1524 Abbot Ave. Unit H,

San Gabriel, CA 91776, USA

J. H. Tran

Orange County Asian Pacific Islander Community Alliance,

Garden Grove, CA, USA

\section{Introduction}

Breast and Cervical Cancer among AAPI Women

Asian Americans and Pacific Islanders (AAPIs) are one of the fastest growing minority groups in the USA and represent approximately $4.5 \%$ of the total population [1]. Furthermore, California is home to approximately 4.8 million AAPIs, the largest in the country [1]. In California, breast cancer is the most common type of cancer among women and the incidence of breast cancer among AAPI women increased by approximately $14 \%$ from 1988 to 2002. During this time, the breast cancer mortality rate among AAPI women residing in California has remained relatively stable despite notable declines among other race/ ethnic groups. This is at least, in part, attributable to the fact that AAPI women continue to have the lowest rate of breast cancer screening in California [2].

AAPI women also have a high incidence of cervical cancer. Although Hispanic women residing in California have approximately twice the risk of developing cervical cancer than other race/ethnic groups, AAPI women have higher rates than non-Hispanic white and African-American women [2]. Furthermore, estimates from 2004 suggest that African Americans (94\%), non-Hispanic whites (86\%), and Hispanics (84\%) are more likely to have reported receipt of a Pap smear in the previous 3 years than AAPI (78\%) women [2].

Although epidemiologic surveillance data regarding breast and cervical cancer among AAPI women are increasingly available, disaggregated data on specific AAPI subgroups remains sparse. There are some data that suggest that subgroups such as Southeast Asian women are 
experiencing disparate rates of cervical cancer. In particular, the incidence rate of cervical cancer among Southeast Asian women has been estimated to be approximately three times higher than non-Hispanic white women [3]. Southeast Asian (SEA) women have substantially higher rates of cervical cancer than any other racial group [4]. Breast cancer has been found to be the most common type of cancer among Pacific Islander (PI) women with high rates found in specific ethnic groups like Chamorros and Samoans [5]. Unfortunately, there is a lack of data regarding breast and cervical cancer screening behavior among SEA and PI women. The available data suggests the need for increased attention to breast and cervical cancer among AAPI women but more research is needed to understand the disparate rates in AAPI subgroups.

\section{REACH 2010 Path for Women Study}

Healthy People 2010 is a national health promotion and disease prevention initiative under the Office of Disease Prevention and Health Promotion of the US Department of Health and Human Services. One of the key preventable health areas addressed by Healthy People 2010 is breast and cervical cancer. Healthy People 2010's leading indicators targets an increase in the proportion of women aged 40 years and older who have received a mammogram within the preceding 2 years from $60 \%$ to $70 \%$ [6]. As part of these initiatives, the Centers for Disease Control and Prevention established the Racial and Ethnic Approaches to Community Health by the year 2010 (REACH 2010) initiative to create community-based collaboratives to address disparities in health including the project titled, "Promoting Access to Health for Pacific Islander and Southeast Asian Women" (PATH for Women) which was initiated in Southern California to eliminate disparities in breast and cervical cancer screening and disease management for seven AAPI populations in Los Angeles and Orange Counties. The PATH for Women project was designed as a community-based participatory research project to assess a 5 -year study in regards to the effects of a culturally tailored, multi-level intervention to increase breast and cervical cancer knowledge, attitudes, and screening behaviors among the participating ethnic AAPI populations.

Knowledge, Attitudes, and Beliefs toward Breast and Cervical Cancer Screening

Breast and cervical cancer screening are important in the reduction of cancer-related mortality. When breast cancer is diagnosed early when confined to the breast, the 5-year survival rate is over $95 \%$ [2]. As for cervical cancer, early diagnosis has resulted in a decline of approximately $40 \%$ in the incidence and mortality associated with invasive cervical cancer [7]. Knowledge, attitudes, and beliefs (KABs) toward disease and illness have been shown to influence breast and cervical cancer screening in specific AAPI populations [7, 8]. Unfortunately, KABs have not been explored as predictors of cancer screenings among SEA women. The current study provides estimates of breast and cervical cancer screening as well as findings from the PATH for Women baseline survey data collection on KABs toward breast and cervical cancer screening behaviors on a large sample of Cambodian, Laotian, Thai, and Tongan women in California. Understanding the knowledge of and perceptions toward breast and cervical cancer screening among AAPI women holds promise for identifying barriers to early detection and could aid in the creation of interventions to promote screening.

\section{Methods}

A detailed description of the sampling strategy, research design, survey development, interviewer training, data collection, and data management techniques implemented in the current study was provided elsewhere [9]. However, a brief review of the research methodology is provided below. Participants were recruited from various community clinics, churches, temples, supermarkets, and other community gathering sites in Northern and Southern California between 2002 and 2003. Sites in Northern California included Sacramento, San Francisco, San Mateo, Alameda, Contra Costa, Monterey, Santa Clara, Sutter County, Solano and San Jose Counties, and Southern California sites primarily included Los Angeles and Orange Counties. Eligible participants included adult women aged 18 and older. The study protocol was approved by the UCLA Human Subjects Institutional Review Board (\# G02-07107-01) and verbal consent was provided by all of the participants. Bilingual community health workers conducted face-to-face interviews in the language most preferred by the participant. As part of a comprehensive baseline questionnaire, demographic and $\mathrm{KAB}$ questions were asked. Questions were translated by bilingual study interviewers into Cambodian, Laotian, Thai, and Tongan, and reviewed by bilingual community leaders prior to administration of the survey. Culturally tailored prompts were developed to help interviewers provide clear, accurate, and understandable descriptions of all medical concepts and terminology contained in the survey. A total of 1,825 individuals were interviewed but 17 participants who were born in the US were excluded from the sample to retain a homogeneous sample of foreign-born AAPI women. The final sample included a total of 1,808 AAPI women from four communities: Cambodian $(n=355)$, Laotian $(n=361)$, Thai $(n=742)$, and Tongan $(n=350)$. 
All data were entered, cross-checked, and analyzed in SPSS 14.0 [10]. A systematic data review was conducted to check for outliers and ensure that the data adequately met the assumptions of the statistical tests prior to analysis [11]. One-way analysis of variance and chi-square statistics were conducted to compare the four ethnic groups on demographic and KABs questions. Missing data were excluded for bivariate analyses.

\section{Results}

\section{Demographic Characteristics}

Thais represented $41 \%$ of the sample followed by Laotians (20.0\%), Cambodians (19.6\%), and Tongans (19.4\%). Adult women between the ages of 26-90 years were included in the study and the average age was 49.9 ( $\mathrm{SD}=$ 11.6). The women had lived in the US between 0 and 47 years with an average residency of 16.3 years $(\mathrm{SD}=8.4)$. Nearly half were unemployed $(49.0 \%)$ at the time of the survey and a majority reported difficulties in the ability to pay for necessities $(84.7 \%)$. However, most had some kind of medical insurance $(66.7 \%)$ at the time of the interview, with the highest proportion of insured women in the Cambodian and Laotian groups. While in the US, 37.5\% did not report receiving any education, $10.7 \%$ received primary and high school education, $15.7 \%$ received college, university, or vocational education, and $36.1 \%$ reported English as a Second Language (ESL) or adult school education. In their birth country, $15.6 \%$ of the total sample reported not receiving any education, $62.4 \%$ reported receiving primary and high school education, $21.1 \%$ college, university, or vocational education, and $0.8 \%$ reported ESL or adult school education. Interestingly, $42.5 \%$ Thais had received college, university, or vocational education in their country of birth whereas only $10.7 \%$ of Tongans, 3.8\% of Laotians, and 3.4\% of Cambodians had received a college education. Lastly, $60 \%$ of the women were married and $40 \%$ were unmarried, of which $4.6 \%$ were living as a married couple.

A large majority of the sample had heard of a mammogram (Cambodians: 87.3\%, Laotians: 83.9\%, Thais: 90.6\%, and Tongans: 93.1\%) and Pap smear (Cambodians: $87.3 \%$, Laotians: $92.5 \%$, Thais: 97.3\%, and Tongans: $86.3 \%$ ). However, when participants were asked if they had received a mammogram, a clinical breast exam (CBE), and Pap smear in their lifetime, rates were far lower. In the total sample, $55.3 \%$ had received mammograms (Cambodians: 50.7\%, Laotians: 62.6\%, Thai: $66.7 \%$, Tongan: $26.0 \%), 68.6 \%$ had received a CBE (Cambodians: $62.5 \%$, Laotians: $79.5 \%$, Thai: $85.8 \%$, Tongan: $23.1 \%$ ), and $71.9 \%$ had received Pap smears
(Cambodians: $71.0 \%$, Laotians: $85.0 \%$, Thai: $89.2 \%$, Tongan: $18.0 \%)$, respectively.

Participants were asked, "In the past two years, what sources of information for breast and cervical cancer have you been exposed to?" Responses were grouped into four categories: (1) health education sources (such as educational brochures or pamphlets and community outreach workers), (2) mass media outlets (such newspapers, radio, and television), (3) family/friends, and (4) health providers. In the total sample, $43.5 \%$ of the women reported receipt of health education regarding breast and cervical cancer from educational brochures, pamphlets, or community outreach workers, $38.0 \%$ reported receiving information from mass media outlets, $58.9 \%$ received information from family or friends, and $18.1 \%$ received breast or cervical cancer information from their health providers. Notably, a high proportion of Cambodians (76.7\%) had reported exposure to health education sources as opposed to other sources of information (mass media: $45.4 \%$, family and friends: $48.7 \%$, and healthcare provider: $11.2 \%$ ). Of the Laotian sample, $37.4 \%$ received information from health education sources, $18.7 \%$ from mass media, $42.3 \%$ from family or friends, and $33.2 \%$ received information about breast and cervical cancer from their healthcare provider. The distribution among the Thai women for source of information was as follows: health education sources $(41.8 \%)$, mass media $(52.3 \%)$, family or friends $(57.1 \%)$, and healthcare provider $(21.8 \%)$. Finally, $39.7 \%$ of the Tongan participants received information from health education sources, $18.7 \%$ from mass media, $87.8 \%$ from family or friends, and 3.8\% from their healthcare provider.

Knowledge, Attitudes, and Beliefs of Breast and Cervical Cancer

Women from all four AAPI groups were asked to identify five symptoms commonly associated with breast cancer. Most recognized that a breast lump (89\%) was a possible symptom of breast cancer. However, a smaller proportion of the sample recognized that a bloody breast discharge $(57.5 \%)$, puckered breast skin $(49.3 \%)$, painful breasts (72.6\%), and change in breast size from normal (62.1\%) were symptoms of breast cancer.

Attitudes and beliefs about breast cancer and screening were assessed. Most of the participants (94.5\%) believed that women with breast cancer can live a normal lifetime if it is discovered and treated early. A majority of the women (96.2\%) also agreed that a mammogram can find breast cancer in its early stages. Finally, $95.3 \%$ of the women believed that if breast cancer is found early, it can be cured. However, when it comes to attitudes about screening for cancer, approximately $56 \%$ of the women believed that a mammogram is only needed when they have symptoms. 
More specifically, $57 \%$ of the women believed that they only needed a mammogram when they had a breast lump. In addition $52.8 \%$ did not believe that there was much they could do to prevent breast cancer. Comprehensive results for the four AAPI groups are provided in Table 1.

Women were asked about their knowledge of risk factors associated with cervical cancer. It is important to note that the survey did not ask questions about cervical cancer symptoms because early stages of cervical cancer tend to by asymptomatic and there are no clear or discrete symptoms associated with cervical cancer. Therefore, inquiring about risk factors which are more commonly known was deemed to be best method of gauging KABs about cervical cancer. Most recognized that the number of sexual partners they had (79.4\%) as well as the number of sexual partners the husband had (74.4\%), increased the risk. However, a smaller proportion recognized that there was an increased risk of cervical cancer related to exposure to cigarette smoke (41.9\%), and the use of birth control pills (55.0\%). Percentages among the ethnic groups are provided in Table 2.

The participants were also asked about their attitudes and beliefs about cervical cancer and screenings (see Table 3). The majority of women seemed to have healthy attitudes regarding cancer and health behavior. Most women agreed that if cancer of the cervix is found early, it can be cured. Many women received encouragement from family or friends to get Pap smears (78.4\%). The majority did not hold certain beliefs such as: "a woman does not need to get Pap smears after she reaches menopause," or that "a woman does not need to get Pap smears after she stops having children," and that "only women who are sexually active should get Pap smears." There were no significant ethnic differences found for this set of questions.

\section{Discussion}

Early detection and treatment of breast and cervical cancer has been shown to prevent morbidity and mortality. The current study highlights disparities in cancer screening among particular racial and ethnic groups within AAPI communities. In addition, important differences and similarities in the knowledge, attitudes, and beliefs regarding breast and cervical cancer screening within the Cambodian, Laotian, Thai, and Tongan communities were described. First and foremost, lifetime breast and cervical cancer screening rates found in the current study were lower than national standards. Rates of cancer screening in the total sample were $55.3 \%, 68.6 \%$, and $71.9 \%$ for mammograms, CBE, and Pap smears, respectively. Significant group differences were found across all three cancer screening behaviors and Thais had the largest proportion of lifetime mammogram (66.7\%), CBE (85.8\%), and Pap smear (89.2\%) rates than any other group. Nevertheless, rates in all four groups were below the $70 \%$ for mammograms and $90 \%$ for Pap smears stipulated in the Healthy People 2010 goals.

Secondly, a large number of women from all four groups reported receiving breast and cervical cancer information from health education, media, and family/friends. However, a strikingly small proportion $(18.2 \%)$ of women had received breast and cervical cancer information from their healthcare provider. Given that previous research has shown that recommendations from medical professionals can impact health related behaviors, interventions targeting healthcare workers could be warranted [7]. However, more research is needed to test the effectiveness of such an intervention in these communities. As well, the study reveals that health education, media, and family/friends are strong resources for health information, suggesting health education efforts also target these outlets.

Thirdly, it was apparent that the knowledge of common symptoms, such as a breast lump and painful breast, were acknowledged by over $70 \%$ of the sample but less common symptoms such as bloody breast discharge, puckered breast skin, and changes in breast size from normal were less often acknowledged to be associated with breast cancer $[12,13]$. In addition, sexual risk factors such as the number of personal sexual partners and the number of sexual partners the husband had were acknowledged to be risk factors for cervical cancer by over $70 \%$ of the sample. However, cigarette smoking and the use of birth control pills were less often recognized as valid risk factors [12, 13]. This suggests that education is still needed in these communities to, better and more deeply, understand the health risks and symptoms to prevent and early detect cancers.

Lastly, attitudes and beliefs concerning breast cancer were surprising. Over half of the women did not believe that they could do anything to prevent breast cancer and felt that they only needed a mammogram if they felt symptoms or had a breast lump. Future research may examine the interplay between attitudes, beliefs, and knowledge in terms of screening. As noted above, even though women had healthy attitudes about preventive screenings, they did not believe that this information applied to them. As well, while they had knowledge about risks, this did not correlate to high rates of utilization. Knowledge alone may not be the most important predictor of screening and does not inherently lead to health behavior. These results strongly support the need for prevention efforts that not only improve knowledge but also address the attitudes and beliefs that may inhibit screening utilization. It is important for physicians and healthcare providers to identify their patients' level of knowledge and beliefs regarding cancer-related risk factors, causes, and symptoms during their interactions [7].

We must note that there are limitations to the study. While the overall sample size is strong, this study only represents a 
Table 1 Attitudes and beliefs about breast cancer

\begin{tabular}{|c|c|c|c|c|c|c|}
\hline & \multirow[t]{2}{*}{ Cambodian $(n=355)$} & \multirow[t]{2}{*}{ Laotian $(n=361)$} & \multirow[t]{2}{*}{ Thai $(n=742)$} & \multirow[t]{2}{*}{ Tongan $(n=350)$} & \multicolumn{2}{|l|}{ Effect } \\
\hline & & & & & $\overline{\chi^{2}}$ & $p$ \\
\hline \multicolumn{7}{|c|}{ Most women with breast cancer can live a normal lifetime if it is discovered and treated early } \\
\hline $\begin{array}{l}\text { Agree } \\
\text { Disagree }\end{array}$ & $\begin{array}{c}345(97.2) \\
10(2.8)\end{array}$ & $\begin{array}{r}331(86.1) \\
50(13.9)\end{array}$ & $\begin{array}{c}729(98.2) \\
13(1.8)\end{array}$ & $\begin{array}{l}323(92.3) \\
27(7.7)\end{array}$ & 76.30 & $<0.001$ \\
\hline \multicolumn{7}{|c|}{ A woman is more likely to get breast cancer if her mother or sister has had it } \\
\hline $\begin{array}{l}\text { Agree } \\
\text { Disagree }\end{array}$ & $\begin{array}{r}269(75.8) \\
86(24.2)\end{array}$ & $\begin{array}{r}263(72.9) \\
98(27.1)\end{array}$ & $\begin{array}{l}585(78.8) \\
157(21.2)\end{array}$ & $\begin{array}{r}293(83.7) \\
57(16.3)\end{array}$ & 13.56 & 0.004 \\
\hline \multicolumn{7}{|c|}{ A woman is more likely to get breast cancer if she eats a diet high in fat } \\
\hline $\begin{array}{l}\text { Agree } \\
\text { Disagree }\end{array}$ & $\begin{array}{l}157(44.2) \\
198(55.8)\end{array}$ & $\begin{array}{l}204(56.5) \\
157(43.5)\end{array}$ & $\begin{array}{l}503(67.8) \\
239(32.2)\end{array}$ & $\begin{array}{l}176(50.3) \\
174(49.7)\end{array}$ & 65.35 & $<0.001$ \\
\hline \multicolumn{7}{|c|}{ A mammogram can find breast cancer in its early stages } \\
\hline $\begin{array}{l}\text { Agree } \\
\text { Disagree }\end{array}$ & $\begin{array}{c}348(98.0) \\
7(2.0)\end{array}$ & $\begin{array}{c}333(92.2) \\
28(7.8)\end{array}$ & $\begin{array}{l}714(96.2) \\
28(3.8)\end{array}$ & $\begin{array}{c}344(98.3) \\
6(1.7)\end{array}$ & 22.77 & $<0.001$ \\
\hline \multicolumn{7}{|c|}{ People get breast cancer because they have lived a bad life } \\
\hline $\begin{array}{l}\text { Agree } \\
\text { Disagree }\end{array}$ & $\begin{array}{l}110(31.0) \\
245(69.0)\end{array}$ & $\begin{array}{l}143(39.6) \\
218(60.4)\end{array}$ & $\begin{array}{l}201(27.1) \\
541(72.9)\end{array}$ & $\begin{array}{r}66(18.9) \\
284(81.1)\end{array}$ & 39.37 & $<0.001$ \\
\hline \multicolumn{7}{|c|}{ A mammogram is only needed if I feel I have symptoms } \\
\hline $\begin{array}{l}\text { Agree } \\
\text { Disagree }\end{array}$ & $\begin{array}{r}297(83.7) \\
58(16.3)\end{array}$ & $\begin{array}{l}112(31.0) \\
249(69.0)\end{array}$ & $\begin{array}{l}529(71.3) \\
213(28.7)\end{array}$ & $\begin{array}{r}77(22.0) \\
273(78.0)\end{array}$ & 436.56 & $<0.001$ \\
\hline \multicolumn{7}{|c|}{ If breast cancer is found early, it can be cured } \\
\hline $\begin{array}{l}\text { Agree } \\
\text { Disagree }\end{array}$ & $\begin{array}{c}340(95.8) \\
15(4.2)\end{array}$ & $\begin{array}{r}325(90.0) \\
36(10.0)\end{array}$ & $\begin{array}{c}738(99.5) \\
4(0.5)\end{array}$ & $\begin{array}{l}320(91.4) \\
30(8.6)\end{array}$ & 62.96 & $<0.001$ \\
\hline \multicolumn{7}{|c|}{ I think I would rather not know if I had breast cancer } \\
\hline $\begin{array}{l}\text { Agree } \\
\text { Disagree }\end{array}$ & $\begin{array}{l}104(29.3) \\
251(70.7)\end{array}$ & $\begin{array}{r}87(24.1) \\
274(75.9)\end{array}$ & $\begin{array}{l}302(40.7) \\
440(59.3)\end{array}$ & $\begin{array}{r}69(19.7) \\
281(80.3)\end{array}$ & 61.91 & $<0.001$ \\
\hline I would un & breast cancer treatmen & is unpleasant or pa & f it would improv & chances of living & & \\
\hline $\begin{array}{l}\text { Agree } \\
\text { Disagree }\end{array}$ & $\begin{array}{r}332(93.5) \\
23(6.5)\end{array}$ & $\begin{array}{c}329(91.1) \\
32(8.9)\end{array}$ & $\begin{array}{c}726(97.8) \\
16(2.2)\end{array}$ & $\begin{array}{c}337(96.3) \\
13(3.7)\end{array}$ & 28.26 & $<0.001$ \\
\hline I would be & to tell my husband or & er if I had breast ce & ecause it would & ge our relationship & & \\
\hline $\begin{array}{l}\text { Agree } \\
\text { Disagree }\end{array}$ & $\begin{array}{r}74(20.8) \\
281(79.2)\end{array}$ & $\begin{array}{r}52(14.4) \\
309(85.6)\end{array}$ & $\begin{array}{l}117(15.8) \\
625(84.2)\end{array}$ & $\begin{array}{r}25(7.1) \\
325(92.9)\end{array}$ & 27.12 & $<0.001$ \\
\hline Breast canc & be cured by tradition & & & & & \\
\hline $\begin{array}{l}\text { Agree } \\
\text { Disagree }\end{array}$ & $\begin{array}{l}131(36.9) \\
224(63.1)\end{array}$ & $\begin{array}{l}113(31.3) \\
248(68.7)\end{array}$ & $\begin{array}{l}189(25.5) \\
553(74.5)\end{array}$ & $\begin{array}{r}69(19.7) \\
281(80.3)\end{array}$ & 30.28 & $<0.001$ \\
\hline I need a $\mathrm{m}$ & gram only when I hav & east lump & & & & \\
\hline $\begin{array}{l}\text { Agree } \\
\text { Disagree }\end{array}$ & $\begin{array}{r}269(75.8) \\
86(24.2)\end{array}$ & $\begin{array}{l}115(31.9) \\
246(68.1)\end{array}$ & $\begin{array}{l}577(77.8) \\
165(22.2)\end{array}$ & $\begin{array}{r}69(19.7) \\
281(80.3)\end{array}$ & 473.12 & $<0.001$ \\
\hline There is no & h that I can do to prev & east cancer & & & & \\
\hline $\begin{array}{l}\text { Agree } \\
\text { Disagree }\end{array}$ & $\begin{array}{l}173(48.7) \\
182(51.3)\end{array}$ & $\begin{array}{l}136(37.7) \\
225(62.3)\end{array}$ & $\begin{array}{l}522(70.4) \\
220(29.6)\end{array}$ & $\begin{array}{l}124(35.4) \\
226(64.6)\end{array}$ & 169.60 & $<0.001$ \\
\hline I am very 1 & to get breast cancer in & etime & & & & \\
\hline $\begin{array}{l}\text { Agree } \\
\text { Disagree }\end{array}$ & $\begin{array}{r}88(24.8) \\
267(75.2)\end{array}$ & $\begin{array}{l}210(58.2) \\
151(41.8)\end{array}$ & $\begin{array}{l}616(83.0) \\
126(17.0)\end{array}$ & $\begin{array}{l}128(36.6) \\
222(63.4)\end{array}$ & 416.30 & $<0.001$ \\
\hline Trauma to & east(s) causes cancer & & & & & \\
\hline $\begin{array}{l}\text { Agree } \\
\text { Disagree }\end{array}$ & $\begin{array}{l}226(63.7) \\
129(36.3)\end{array}$ & $\begin{array}{l}202(56.0) \\
159(44.0)\end{array}$ & $\begin{array}{l}461(62.1) \\
281(37.9)\end{array}$ & $\begin{array}{r}306(87.4) \\
44(12.6)\end{array}$ & 93.79 & $<0.001$ \\
\hline Breast canc & caused by bad winds & & & & & \\
\hline $\begin{array}{l}\text { Agree } \\
\text { Disagree }\end{array}$ & $\begin{array}{c}16(4.5) \\
339(95.5)\end{array}$ & $\begin{array}{r}78(21.6) \\
283(78.4)\end{array}$ & $\begin{array}{l}45(6.1) \\
697(93.9)\end{array}$ & $\begin{array}{c}20(5.7) \\
330(94.3)\end{array}$ & 93.05 & $<0.001$ \\
\hline Breast canc & caused by (bad) spirits & & & & & \\
\hline $\begin{array}{l}\text { Agree } \\
\text { Disagree }\end{array}$ & $\begin{aligned} 23 & (6.5) \\
332 & (93.5)\end{aligned}$ & $\begin{array}{r}50(13.9) \\
311(86.1)\end{array}$ & $\begin{array}{c}28(3.8) \\
714(96.2)\end{array}$ & $\begin{array}{r}39(11.1) \\
311(88.9)\end{array}$ & 41.67 & $<0.001$ \\
\hline
\end{tabular}


Table 2 Knowledge of cervical cancer risk factors

\begin{tabular}{|c|c|c|c|c|c|c|}
\hline \multirow{2}{*}{$\begin{array}{l}\text { A woman is more likely to get } \\
\text { cervical cancer if: }\end{array}$} & \multirow{2}{*}{$\begin{array}{l}\text { Cambodian } \\
(n=355)\end{array}$} & \multirow{2}{*}{$\begin{array}{l}\text { Laotian } \\
(n=361)\end{array}$} & \multirow{2}{*}{$\begin{array}{l}\text { Thai } \\
(n=742)\end{array}$} & \multirow{2}{*}{$\begin{array}{l}\text { Tongan } \\
(n=350)\end{array}$} & \multicolumn{2}{|l|}{ Effect } \\
\hline & & & & & $\chi^{2}$ & $p$ \\
\hline \multicolumn{7}{|c|}{ She began having sex at an early age } \\
\hline Yes & $216(60.8)$ & $214(59.3)$ & $473(63.7)$ & $203(58.0)$ & \multirow[t]{2}{*}{4.11} & \multirow[t]{2}{*}{0.249} \\
\hline No & $139(39.2)$ & $147(40.7)$ & $269(36.3)$ & $147(42.0)$ & & \\
\hline \multicolumn{7}{|l|}{ She has had many sexual partners } \\
\hline Yes & $294(82.8)$ & $282(78.1)$ & $586(79.0)$ & $275(78.6)$ & \multirow[t]{2}{*}{3.13} & \multirow[t]{2}{*}{0.372} \\
\hline No & $61(17.2)$ & 79 (21.9) & $156(21.0)$ & $75(21.4)$ & & \\
\hline \multicolumn{7}{|c|}{ Her husband has had many sexual partners } \\
\hline Yes & $267(75.2)$ & $272(75.3)$ & $548(73.9)$ & $260(74.3)$ & \multirow[t]{2}{*}{0.402} & \multirow[t]{2}{*}{0.940} \\
\hline No & $88(24.8)$ & 89 (24.7) & $194(26.1)$ & $90(25.7)$ & & \\
\hline \multicolumn{7}{|l|}{ She is exposed to cigarette smoke } \\
\hline Yes & $146(41.1)$ & $176(48.8)$ & $302(40.7)$ & $134(38.3)$ & \multirow[t]{2}{*}{9.37} & \multirow[t]{2}{*}{0.025} \\
\hline No & $209(58.9)$ & $185(51.2)$ & $440(59.3)$ & $216(61.7)$ & & \\
\hline \multicolumn{7}{|l|}{ She has poor personal hygiene } \\
\hline Yes & $299(84.2)$ & $280(77.6)$ & $649(87.5)$ & $259(74.0)$ & \multirow[t]{2}{*}{36.5} & \multirow[t]{2}{*}{$<0.001$} \\
\hline No & $56(15.8)$ & $81(22.4)$ & $93(12.5)$ & $91(26.0)$ & & \\
\hline \multicolumn{7}{|c|}{ She uses an intrauterine device (IUD) } \\
\hline Yes & $261(73.5)$ & $248(68.7)$ & $489(65.9)$ & $213(60.9)$ & \multirow[t]{2}{*}{13.67} & \multirow[t]{2}{*}{0.003} \\
\hline No & $94(26.5)$ & $113(31.3)$ & $253(34.1)$ & $137(39.1)$ & & \\
\hline \multicolumn{7}{|l|}{ She uses birth control pills } \\
\hline Yes & $225(63.4)$ & $223(61.8)$ & $348(46.9)$ & $198(56.6)$ & \multirow[t]{2}{*}{36.78} & \multirow[t]{2}{*}{$<0.001$} \\
\hline No & $130(36.6)$ & $138(38.2)$ & $394(53.1)$ & $152(43.4)$ & & \\
\hline
\end{tabular}

convenience sampling of women in the targeted communities and may not be generalizable to other AAPI communities. As well, the study data is cross-sectional and limits our examination of screening behavior to one point in time. The survey design and translation are also issues which may limit the generalizability and comparability of findings. While particular questions were taken from standardized surveys, such as the National Health Interview Survey and the
Table 3 Attitudes and beliefs about cervical cancer

\begin{tabular}{|c|c|c|c|c|c|c|}
\hline & \multirow[t]{2}{*}{ Cambodian $(n=355)$} & \multirow[t]{2}{*}{ Laotian $(n=361)$} & \multirow[t]{2}{*}{ Thai $(n=742)$} & \multirow[t]{2}{*}{ Tongan $(n=350)$} & \multicolumn{2}{|l|}{ Effect } \\
\hline & & & & & $\chi^{2}$ & $p$ \\
\hline \multicolumn{7}{|c|}{ If cancer of the cervix is found early, it can be cured } \\
\hline Yes & $349(98.3)$ & $348(96.4)$ & $733(98.8)$ & $349(99.7)$ & \multirow[t]{2}{*}{13.71} & \multirow[t]{2}{*}{0.003} \\
\hline No & $6(1.7)$ & $13(3.6)$ & $9(1.2)$ & $1(0.3)$ & & \\
\hline \multicolumn{7}{|c|}{ I have family or friends who encourage me to get Pap smears } \\
\hline Yes & $293(82.5)$ & $225(62.3)$ & $611(82.3)$ & $289(82.6)$ & \multirow[t]{2}{*}{69.14} & \multirow[t]{2}{*}{$<0.001$} \\
\hline No & $62(17.5)$ & $136(37.7)$ & $131(17.7)$ & $61(17.4)$ & & \\
\hline \multicolumn{7}{|c|}{ A woman does not need to get Pap smears after she reaches menopause } \\
\hline Yes & $107(30.1)$ & $56(15.5)$ & $47(6.3)$ & $23(6.6)$ & \multirow[t]{2}{*}{137.17} & \multirow[t]{2}{*}{$<0.001$} \\
\hline No & $248(69.9)$ & $305(84.5)$ & $695(93.7)$ & $327(93.4)$ & & \\
\hline \multicolumn{7}{|c|}{ A woman does not need to get Pap smears after she stops having children } \\
\hline Yes & $37(10.4)$ & $45(12.5)$ & $38(5.1)$ & $26(7.4)$ & \multirow[t]{2}{*}{20.93} & \multirow[t]{2}{*}{$<0.001$} \\
\hline No & $318(89.6)$ & $316(87.5)$ & $704(94.9)$ & $324(92.6)$ & & \\
\hline \multicolumn{7}{|c|}{ Only women who are sexually active should get Pap smears } \\
\hline Yes & $122(34.4)$ & $86(23.8)$ & $69(9.3)$ & $117(33.4)$ & \multirow[t]{2}{*}{129.56} & \multirow[t]{2}{*}{$<0.001$} \\
\hline No & $233(65.6)$ & $275(76.2)$ & $673(90.7)$ & $233(66.6)$ & & \\
\hline \multicolumn{7}{|c|}{ I'm too busy to get Pap smears } \\
\hline Yes & $48(13.5)$ & $38(10.5)$ & $215(29.0)$ & $37(10.6)$ & \multirow[t]{2}{*}{88.89} & \multirow[t]{2}{*}{$<0.001$} \\
\hline No & $307(86.5)$ & $323(89.5)$ & $527(71.0)$ & $313(89.4)$ & & \\
\hline
\end{tabular}


California Health Interview Survey, some of the questions could not be asked verbatim because they may have been considered inappropriate.

Southeast Asian and Pacific Islander groups such as Cambodians, Laotians, Thais, and Tongans are often overlooked in the literature and little if any disaggregated data exists on these communities. This article contributes to the literature specific information about specific subgroups that face clear health disparities and for whom better interventions and resources can be directed with such information. Nevertheless, the current study brought about more questions than answers. Further research should address the specific constellation of factors that lead to these disparities in breast and cervical cancer screening. Possible reasons include but are not limited to the lack of insurance, competing resources and priorities, lack of knowledge regarding available screening and treatment services, money and time constraints, language barriers, feelings of embarrassment and beliefs about the invasiveness of screening procedures.

Open Access This article is distributed under the terms of the Creative Commons Attribution Noncommercial License which permits any noncommercial use, distribution, and reproduction in any medium, provided the original author(s) and source are credited.

\section{References}

1. Census of the Population (2000) (SF 4), United States. Bureau of the Census
2. ACS (2007) California cancer facts and figures 2007. American Cancer Society: California Cancer Registry

3. Taylor V, Jackson J, Schwartz S, Tu S, Thompson B (1996) Cervical cancer among Asian American women: a neglected public health problem? Asian Am Pac Isl J Health 4(4):327342

4. Tanjasiri S, Kagawa-Singer M, Nguyen T, Foo M (2002) Collaborative research as an essential component for addressing cancer disparities among Southeast Asian and Pacific Islander women. Health Promot Pract 3(2):144-154

5. Tanjasiri S, Sablan-Santos L (2001) Breast cancer screening among Chamorro women in Southern California. J Women's Health Gend-Based Med 10(5):479-485

6. Kagawa-Singer M, Pourat N (2000) Asian American and Pacific Islander breast and cervical carcinoma screening rates and Healthy People 2000 Objectives. Cancer 89:696-705

7. Phipps E, Cohen MH, Sorn R, Braitman LE (1999) A pilot study of cancer knowledge and screening behaviors of Vietnamese and Cambodian women. Health Care Women Int 20:195-207

8. Ho V, Yamal JM, Atkinson EN, Basen-Engquist K, TortoleroLuna G, Follen M (2005) Predictors of breast and cervical screening in Vietnamese women in Harris County, Houston, Texas. Cancer Nurs 28(2):119-129

9. Kagawa-Singer M, Tanjasiri S, Lee S et al (2006) Breast and cervical cancer control among Pacific Islander and Southeast Asian women: participatory action research strategies for baseline data collections in California. J Cancer Educ 21(Supplement): S53-S60

10. SPSS for Windows (2005) [Software]. Version 14.0. SPSS, New York

11. Tabachnick BG, Fidell LS (2007) Using multivariate statistics, 5th edn. Pearson Education, New York

12. ACS (2008) California cancer facts and figures 2008. In: Society $\mathrm{AC}$, ed California Cancer Registry

13. Institute NC (2008) What you need to know about Breast Cancer. In: Services USDoHaH ed National Institutes of Health 